\title{
Failure analysis on retrieved ultra high molecular weight polyethylene (UHMWPE) acetabular cups
}

N.D.L. Burger ${ }^{\mathrm{a},}$, P.L. de Vaal ${ }^{\mathrm{b},}$ and J.P. Meyer ${ }^{\mathrm{a},}$

${ }^{a}$ Department of Mechanical and Aeronautical Engineering, University of Pretoria, Pretoria 0001, South Africa

${ }^{b}$ Department of Chemical Engineering, University of Pretoria, Pretoria, South Africa Received 30 August 2006; accepted 18 November 2006. Available online 27 February 2007.

\begin{abstract}
Retrievals obtained after revision surgery, provide valuable information on the rate of wear and the causes of wear that take place in vivo. The aim of this study was to perform a root cause failure analysis to determine the principle reason for mechanical failure on failed acetabular cups, retrieved during revision surgery, by making use of sound engineering failure analysis techniques. The bearing couples varied between steel on UHMWPE and ceramic on UHMWPE. The information gained during this analysis brought to the four that the principle mode of mechanical failure for acetabular cups is overheating of the UHMWPE. The resulting overheating is mainly due to a lack of good and/or sufficient lubrication.
\end{abstract}




\section{Article Outline}

1. Introduction

2. Analysis of retrievals

3. Results

3.1. Cracks in acetabular components

3.1.1. Cracks on the rim of the cup

3.1.2. Cracks inside the bearing area

3.2. Scratches

3.2.1. Scratches caused by third-body wear

3.2.2. Scratches formed by normal UHMWPE wear products

3.3. Plastic flow

3.4. Adhesion wear

4. Postulate for mechanical failure of acetabular cups

5. Conclusion

Acknowledgements

References

\section{Introduction}

Owing to the crippling nature of arthritis, the medical profession has been trying for well over a century to successfully treat this debilitating disease especially when it attacks the hip joints [1] and [2]. Total hip arthroplasty has been offered to younger and more active patients with increasing frequency over the last decade as the clinical success of this operation continues to be validated. The general concept of prosthesis used for total hip arthroplasty is a modular system consisting of an acetabular component, a femoral component and a femoral ball fitted between the acetabulum and femoral component to 
establish the articulating effect [3], [4] and [5]. The major cause for these transplants is osteoarthritis.

Only a small number of countries are keeping records of the state of hip surgeries performed. The leading hip replacement registers are the "Swedish National Hip Arthroplasty Register" [3], the "Norwegian Arthroplasty register" [6] and the Report by the "Australian Orthopaedic Association" [5] and [7]. According to these reports, the number of primary procedures performed per year is 17,378 in Australia for the period 1/7/2001 to 30/6/2002, just over 11,000 in Sweden for the year 2000, and 6108 in Norway for the period 2002. These numbers equate to approximately 110-120 total hip replacements (THR) per 100,000 inhabitants per year. It is estimated that the total number of primary replacements in the United States of America amounts to approximately 200,000 per year [4].

Revision hip replacement is the exchange or removal of one or both components [3].

According to the Swedish, Australian and Norwegian hip registers the major cause for revision hip replacement is a phenomenon known as aseptic loosening, resulting from osteolysis (Fig. 1) [8], [9], [10], [11], [12] and [13]. Osteolysis occurs as a response to implant-derived particulate debris, and possibly other stimuli, resulting in increased local osteolastic bone resorption. Therefore the major cause of osteolysis is polyethylene wear debris generated during activity [5] and [7]. 


\section{Diagnosis - revision hip replacement}

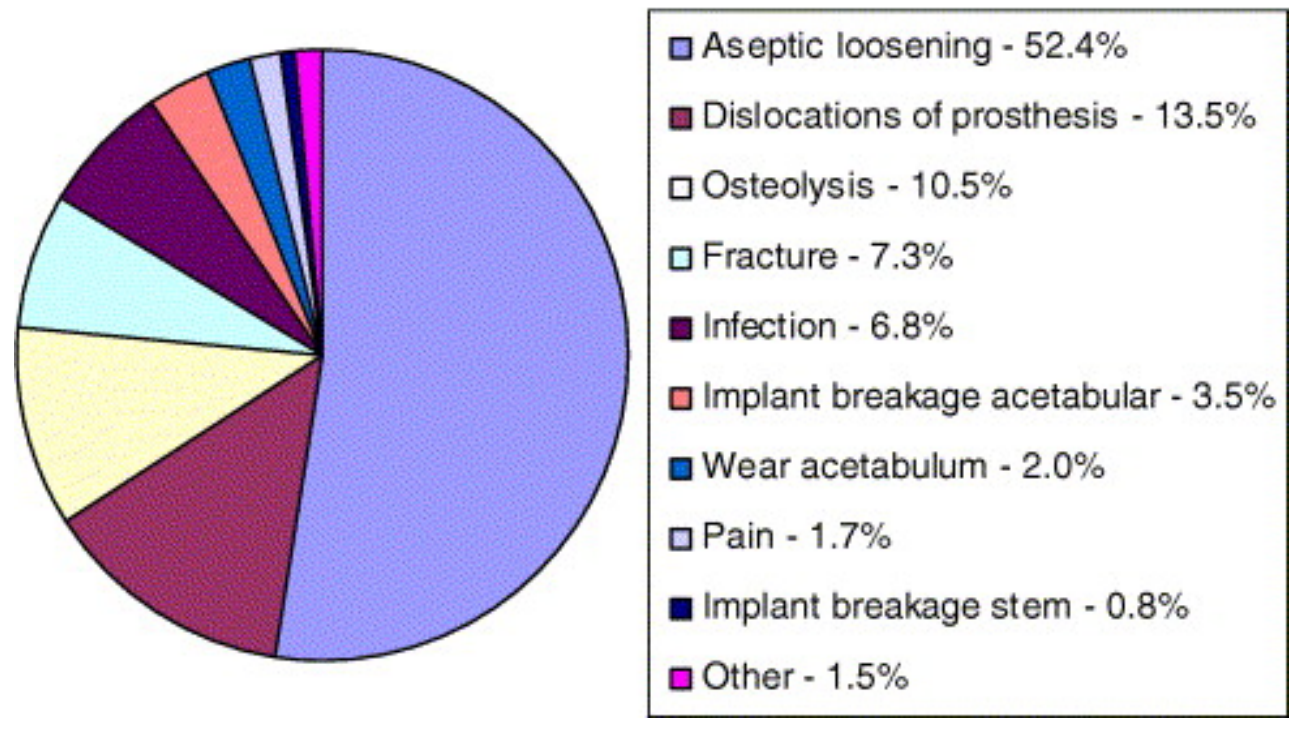

Fig. 1. Statistics of diagnosis resulting in revision surgery hip replacement [5] and [7].

The survival rates from the various prostheses design various drastically. According to Havelin et al. [6] the survival rate of the various designs varies between $60 \%$ at 15 years to as high as $90 \%$ at 15 years. The aim of this study is to determine the main reason for mechanical failure of the retrieved acetabular components.

\section{Analysis of retrievals}

Retrievals obtained after revision surgery provided valuable information with respect to the causes of wear that take place in vivo. The components investigated were retrieved from one centre, properly marked and the details of the patients were noted for further reference. In all, 57 components were retrieved. Forty-seven (47) components were brought to the laboratory for an engineering investigation into the causes of mechanical failure. The relevant ISO standard for the removal and handling of retrievals was followed [14]. The bearing couples of the retrievals varied between steel on UHMWPE and ceramic on UHMWPE. 
A second investigation was conducted making use of a further five components retrieved during revision surgery. During this second study all the freshly retrieved components were analysed in a biochemistry laboratory within $1 \mathrm{~h}$ after removal from the patient. The purpose of this investigation was to try and determine if any proteins were deposited inside the cup. These components were not cleaned in theatre but were supplied as retrieved. The discussion on this analysis does not form part of this article but is given Burger [15].

A third investigation was conducted making use of a further five freshly retrieved components. These retrievals also included tissue removed from the patients. The purpose of this investigation was to find wear debris on either the retrieved components or in the tissue surrounding the prosthesis in vivo to enable the qualification of the mechanism creating this debris. The complete analysis is discussed in Burger [15] but some of the results will be shown here as proof to the cause of mechanical failure of the acetabular cups.

During this investigation, six techniques were used to inspect and analyse the retrieved components namely visual inspection, colour dye penetrant, stereo microscope, scanning electron microscope, electrophoresis and mass-spectrometric analysis.

\section{Results}

The 47 components used in the initial study were retrieved from 24 male and 23 female patients. All of the components had reached the end of their usable life, in vivo, after an average of eight years and three months in service and were manufactured from UHMWPE. Of the 47 components 9 were polyethylene liners implanted with metalbacking and the rest (38) were implanted only with PMMA cement. The service life in these cases varied from 1 year to 23 years and 5 months in vivo. The retrieved acetabular cups were from various manufacturers. In all cases, the reason for revision surgery was a loose acetabular cup causing severe pain and discomfort to the patient. The statistical analysis of 47 retrieved acetabular cups with in total 125 defects is in Table 1. 
openUP (May 2007)

Table 1.

Statistical analysis of retrieved cups, with in total 125 defects

\begin{tabular}{|l|l|l|l|}
\hline Defect & $\begin{array}{l}\text { Number of } \\
\text { defects }\end{array}$ & Percentage & Comments \\
\hline Mechanical damage & 18 & 38 & $\begin{array}{l}\text { Caused by misalignment or } \\
\text { movement after aseptic loosening }\end{array}$ \\
\hline Cracks & 11 & 23 & $\begin{array}{l}\text { Cups with metal backing in } \\
\text { specific series prone to cracks on } \\
\text { rim }\end{array}$ \\
\hline Plastic flow & 29 & 62 & $\begin{array}{l}\text { More prominent when ceramic } \\
\text { femoral head is used }\end{array}$ \\
\hline Scratches (visual) & 21 & 45 & Caused by third-body wear \\
\hline Adhesion wear & 23 & 49 & $\begin{array}{l}\text { Only present when ceramic } \\
\text { femoral head was used }\end{array}$ \\
\hline $\begin{array}{l}\text { Wear particles } \\
\text { embedded in base } \\
\text { material }\end{array}$ & 22 & 47 & $\begin{array}{l}\text { Secondary effect or particles that } \\
\text { originate outside the bearing }\end{array}$ \\
\hline Flaking & 1 & 2 & Most likely a material defect \\
\hline & 125 & 100 & \\
\hline Total & & & \\
\hline
\end{tabular}

The percentage is based on the number of occurrences per defect in 47 cups.

All the retrieved cups showed signs of excessive wear and/or creep. In four cases, there were catastrophic failures. An example of a catastrophic failure is shown in Fig. 2. In the second cup (Fig. 3), something was wrong with the base material, as the material started delaminating within a year after implantation. 


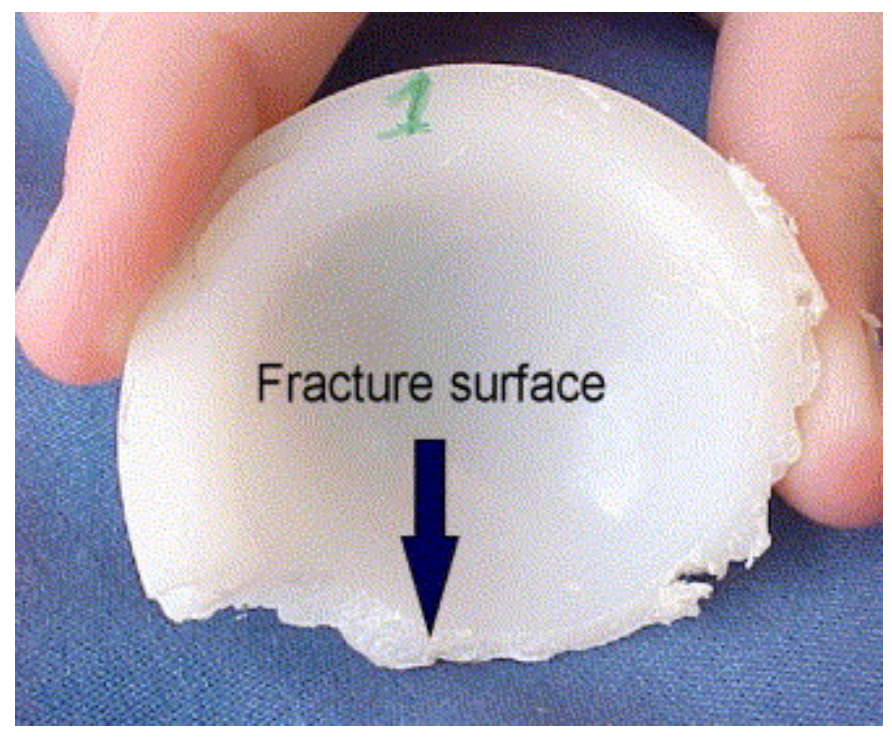

Fig. 2. Acetabular cup with catastrophic failure showing fracture surface.

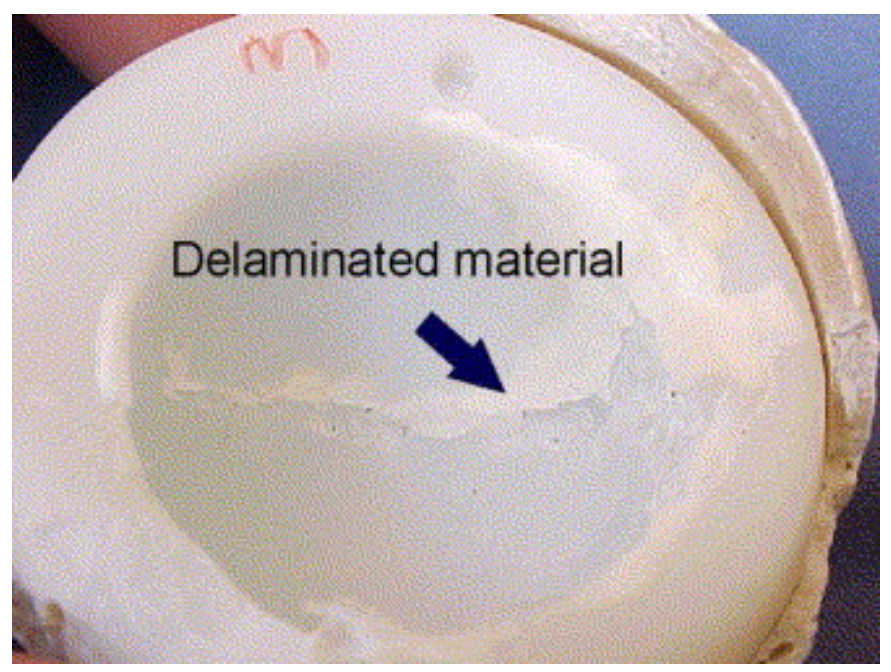

Fig. 3. Acetabular cup with delaminated material visible on inside of cup on bearing surface.

A discussion on the defects found in the various acetabular cups will be discussed followed by a final postulate for the cause of mechanical failure. 


\subsection{Cracks in acetabular components}

During the retrieval study various acetabular components with cracks in the base material were identified. The cracks appear in various locations within the cup, but the cracks are either, cracks on the rim of the cup, or cracks inside the bearing area. The failure analysis of the two different categories is dealt with separately.

\subsubsection{Cracks on the rim of the cup}

Various metal back acetabular components fitted with UHMWPE liners where cracks were visible on the rim of the cup were retrieved as shown in Fig. 4. Apart from the cracks on the rim of the cup, delamination in the area where the rim meets up with the body of the cup was also visible. This delamination varied from small localised areas to a single retrieved cup where this delamination was on the complete circumference of the cup. A cross section of a cup with this delamination visible is shown in Fig. 5.

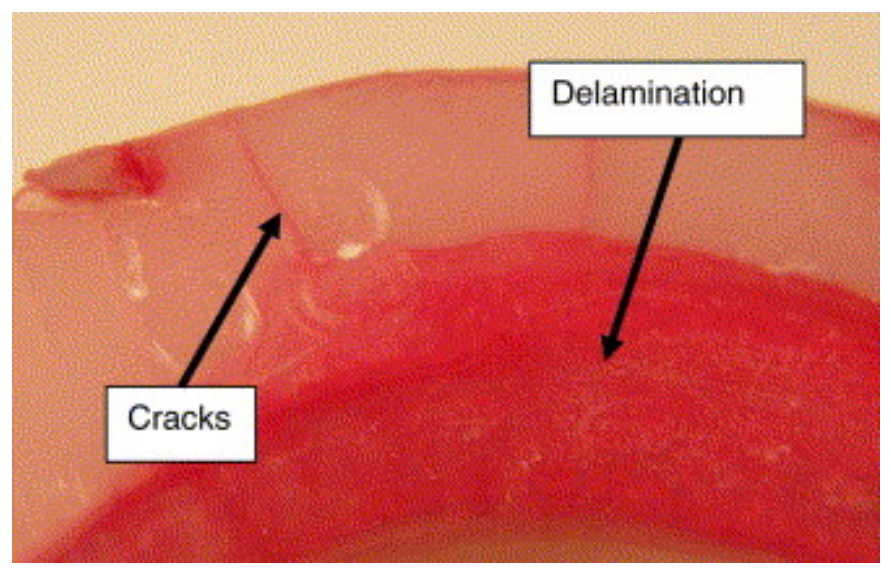

Fig. 4. Metal back acetabular cup with cracks and delamination on rim of cup. 


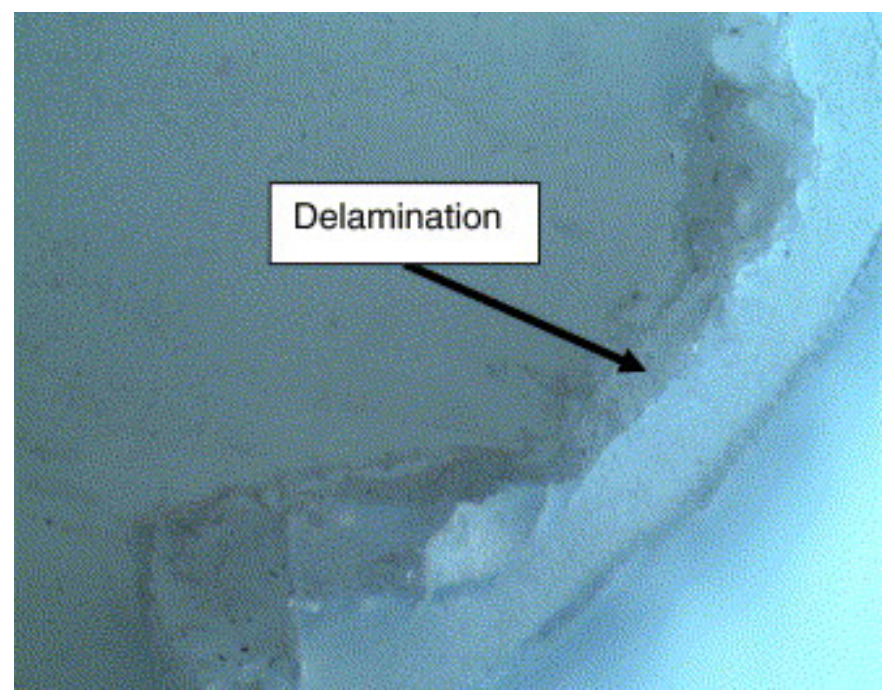

Fig. 5. Cross section of acetabular cup showing delamination on the rim of the cup (magnification 20×).

This failure of cracks and accompanying delamination on the rim of the cup were only seen in metal back cups and also only in the metal back cups from one specific manufacturer. On closer inspection, it was noted that the UHMWPE liner does not fit snugly into the metal backing allowing the resultant forces in the hip joint to be transmitted into the pelvis via the rim of the UHMWPE liner only. This principle is schematically shown in Fig. 6.
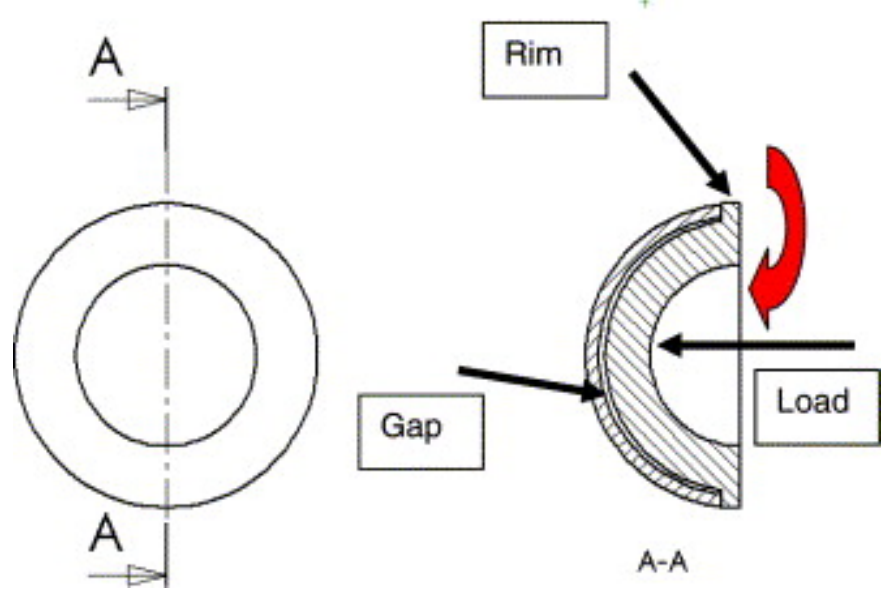
Fig. 6. Schematic layout of UHMWPE liner not fitting snugly into metal backing.

As can be seen from Fig. 6, there is a small gap between the UHMWPE liner and the metal backing. The load coming into the bearing area will now deform the cup resulting in a bending moment with the corresponding bending stress in the rim of the cup. As the patient is walking, this load will vary according to the load profiles as defined in literature [16], [17] and [18], resulting in a dynamic load input into the rim of the UHMWPE that can lead to the fatigue failure that is manifested in the form of cracks and the delamination of the rim interface.

From the data presented, it can be accepted that this failure is due to an error either during the design or during the manufacturing process of the metal backing or the UHMWPE liner. As this defect is not a result of the wear mechanism active in vivo, this defect will not be investigated further.

\subsubsection{Cracks inside the bearing area}

Cracks inside the bearing area can lead to the catastrophic failure of an acetabular component as can be seen in Fig. 2. Cracks in the bearing area are fairly common as can be seen in Fig. 7. On closer examination, making use of dye penetrant spray and the use of an electron microscope, the origin of these cracks can be established. The cracks originate in areas where severe adhesion wear has taken place. A crack starting from an area of adhesion wear can be seen in the electron microscope picture as presented in Fig. 8. 


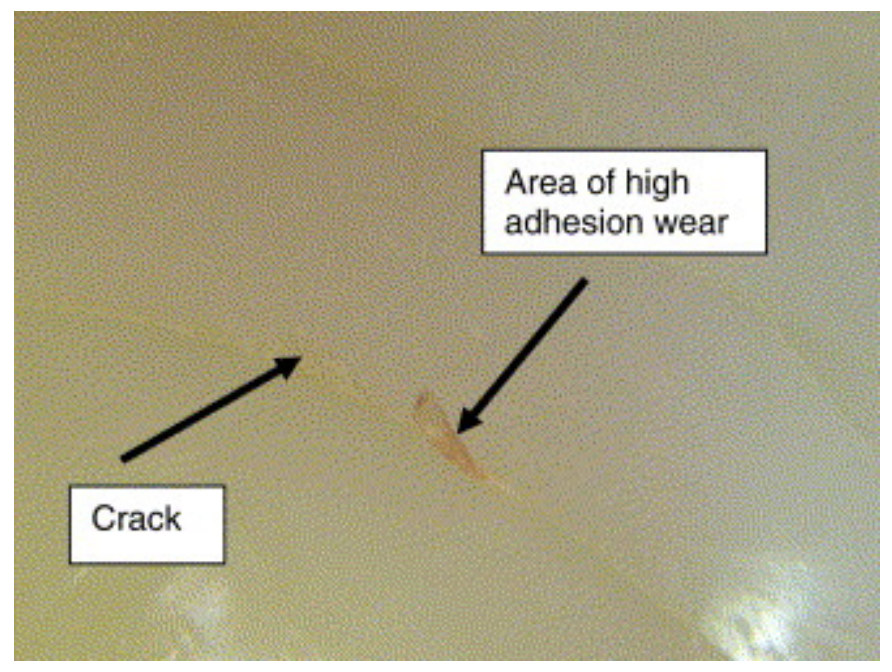

Fig. 7. Crack on bearing surface on inside of acetabular cup.

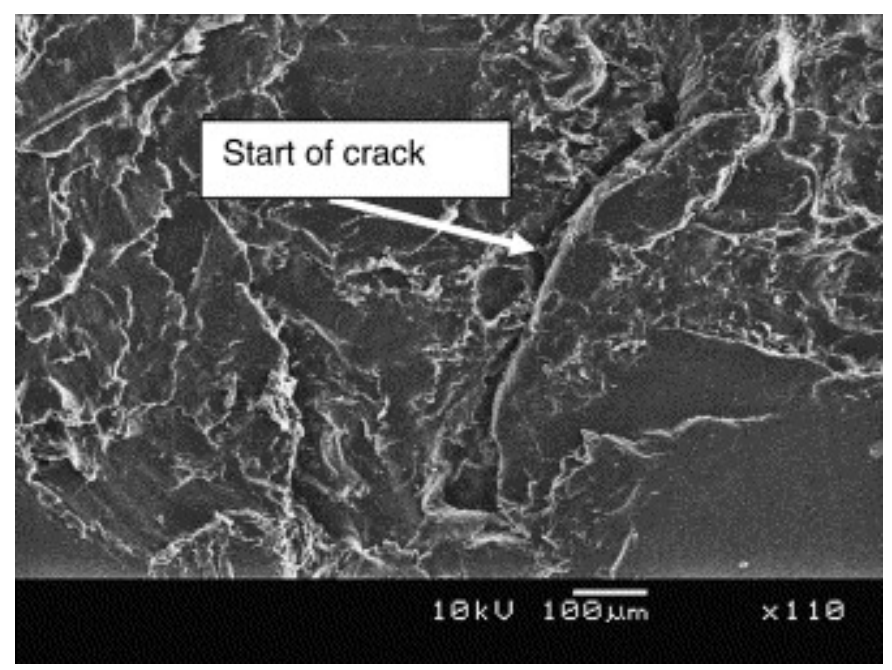

Fig. 8. Electron microscope analysis of adhesion wear area (magnification 110×).

Under the electron microscope (Fig. 8), it would seem that as the top layer of the material is being ripped away from the base material by adhering to the femoral head, craters are formed giving rise to areas with high stress concentrations. A crater under the surface after the removal of the top layer of material can be seen in Fig. 9. Under the dynamic loading conditions, these stress raisers will lead to the formation of long cracks, which can lead to catastrophic failures of the acetabular component. 


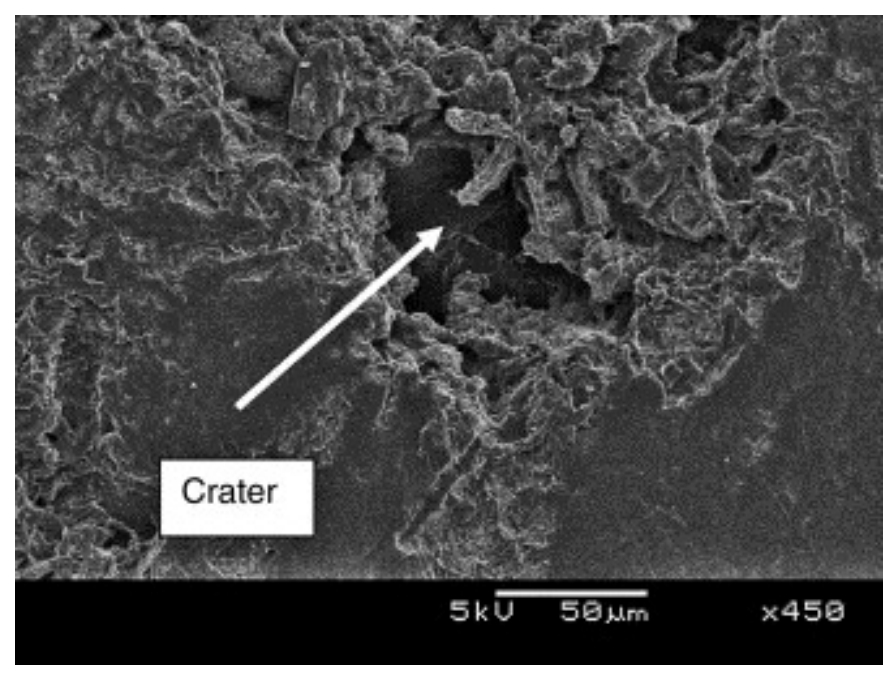

Fig. 9. Crater under the surface after adhesion wear (magnification 450×).

From the data presented it is most probable that the root cause for the formation of the cracks on the bearing area is the uneven removal of the surface of the bearing area by means of adhesion wear. This uneven removal will result in stress raisers in the form of craters which under the continuous dynamic loading will result in the formation of cracks.

It can be concluded that the cracks on the bearing surface are secondary to the formation of areas of uneven material as a result of adhesion wear. The formation of these areas is investigated further and will be discussed later.

\subsection{Scratches}

The scratches found on the bearing surface of the retrieved acetabular cups can again be classified into scratches caused by third-body wear particles and scratches formed by normal UHMWPE wear products. The failure analysis to establish the root cause for the formation of the scratches will be dealt with separately. 


\subsubsection{Scratches caused by third-body wear}

The entering of foreign particles (third body) into the bearing is not that uncommon. These particles normally originate from the PMMA cement with which the implant is fixated. An acetabular cup with severe signs of third-body wear is shown in Fig. 10. In this specific case glass ionomer cement was used for the fixation of the implant. This type of cement is no longer in use and has been replaced with PMMA cement. This type of defect is not a direct result of the active wear mechanism in the acetabular cup and is therefore not investigated further.

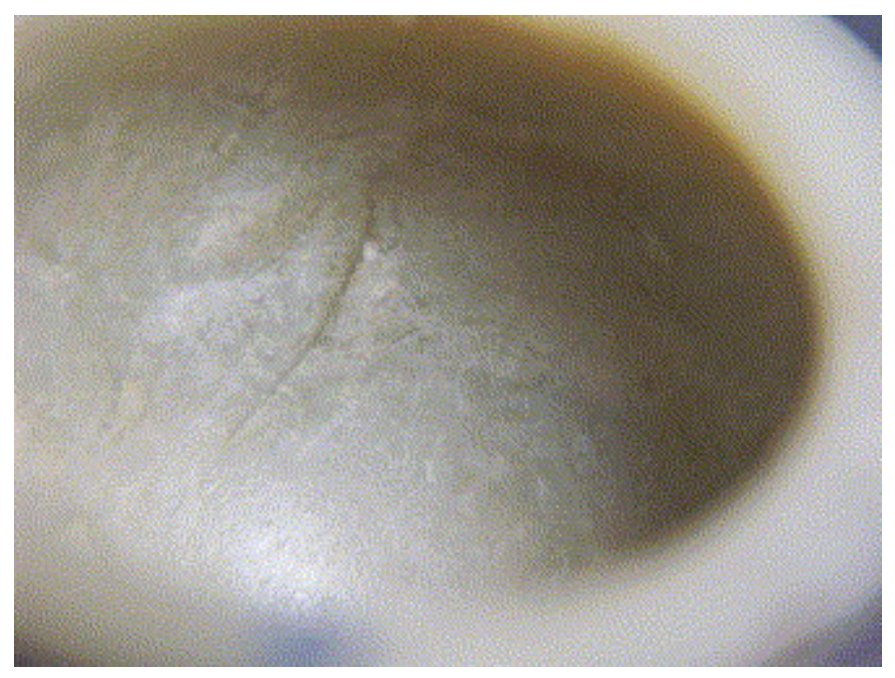

Fig. 10. Acetabular cup with severe scratches on inside.

\subsubsection{Scratches formed by normal UHMWPE wear products}

In all the acetabular components retrieved, scratches as a result of the normal wear products floating around in the bearing area can be observed. The majority of these scratches are too small to see visually and it can only be seen under a magnifying glass. Throughout the literature reference is made to multidirectional fine scratches [19], [20] and [21], which are not easily visible to the naked eye. An acetabular cup with multidirectional fine scratches under a magnification of 20× can be seen in Fig. 11. (Note that the original machining marks are also visible in the Fig. 11.) 


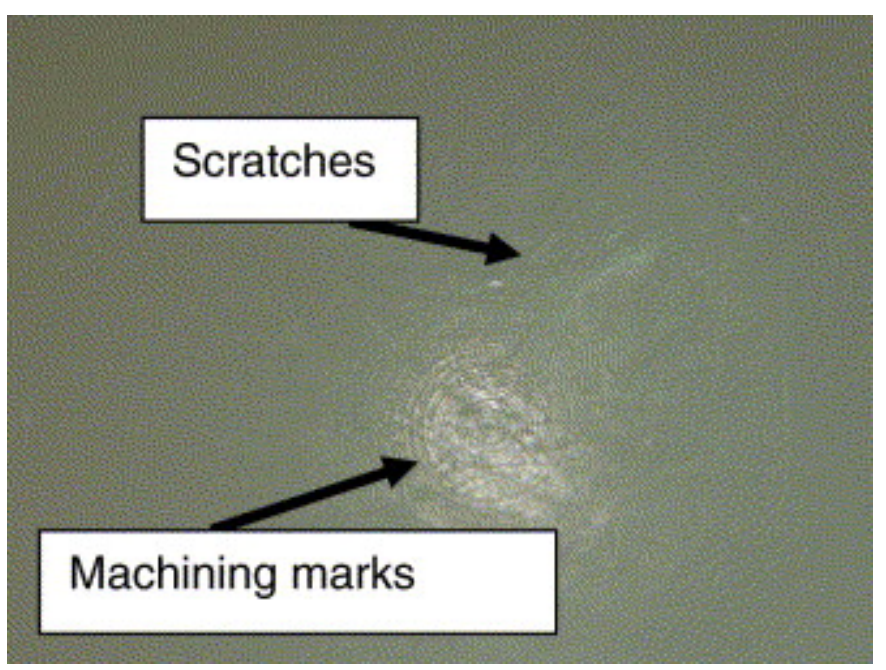

Fig. 11. Acetabular cup with multidirectional fine scratches and with machining marks still visible (magnification 20×).

Scratches visible to the naked eye are also seen in some of the retrieved acetabular cups. When inspecting the acetabular components with a magnifying glass, treating it with dye penetrant spray and investigating under an electron microscope, the size and magnitude of these scratches become evident. The first impression is that this type of scratch must be the result of a third-body particle floating around in the bearing area. An acetabular cup with this type of scratch is shown in Fig. 12. 


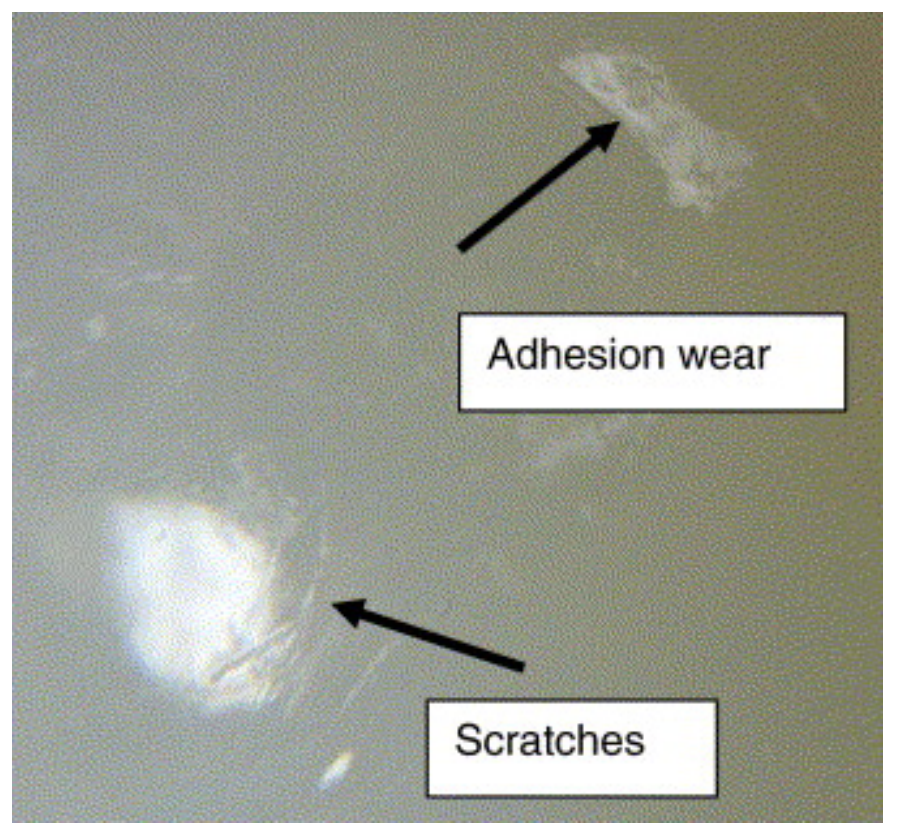

Fig. 12. Bearing area with signs of large scratches and an area with adhesion wear.

Under the electron microscope, it is observed that these scratches are not fine, multidirectional scratches, but are scratches that had been formed by debris floating around in the joint. The scratches as indicated in Fig. 12 under higher magnification in the electron microscope can be seen in Fig. 13. The scratches have been encircled to facilitate the finding of scratches under the electron microscope. In the area of the scratches, a number of white dots are visible, which would appear as if they are pieces of PMMA cement that had entered the bearing area causing the resulting damage. In Fig. 14, the path of one of these particles can be seen under higher magnification with the end clearly visible where the particle came to a standstill. The final path of the particle is visible in Fig. 15, showing the ploughing marks of the particle as it was destroying the bearing surface. 


\section{openUP (May 2007)}

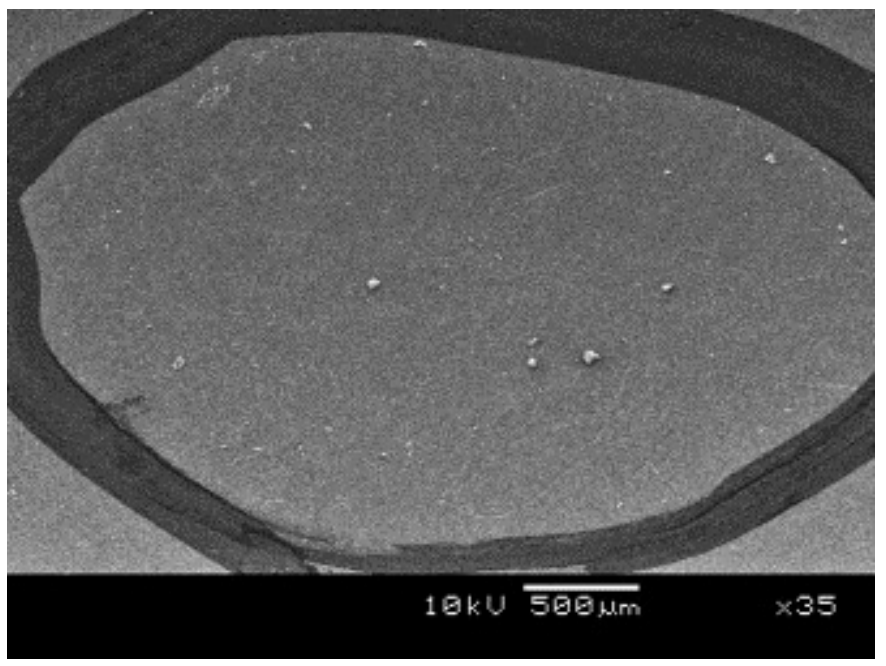

Fig. 13. Scratches on bearing surface with white particles visible (magnification 35×).

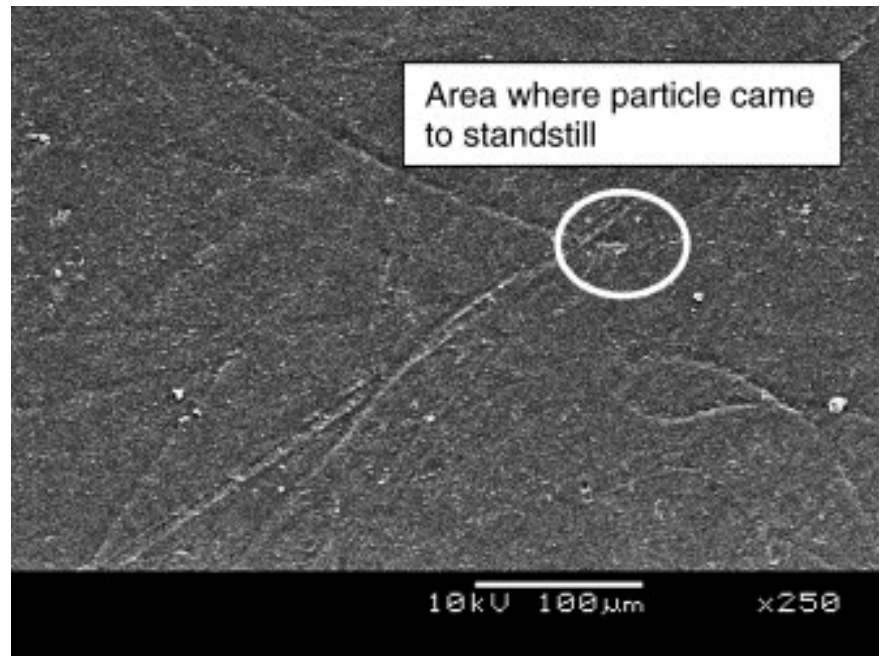

Fig. 14. Scratch mark on bearing surface (magnification 250×). 


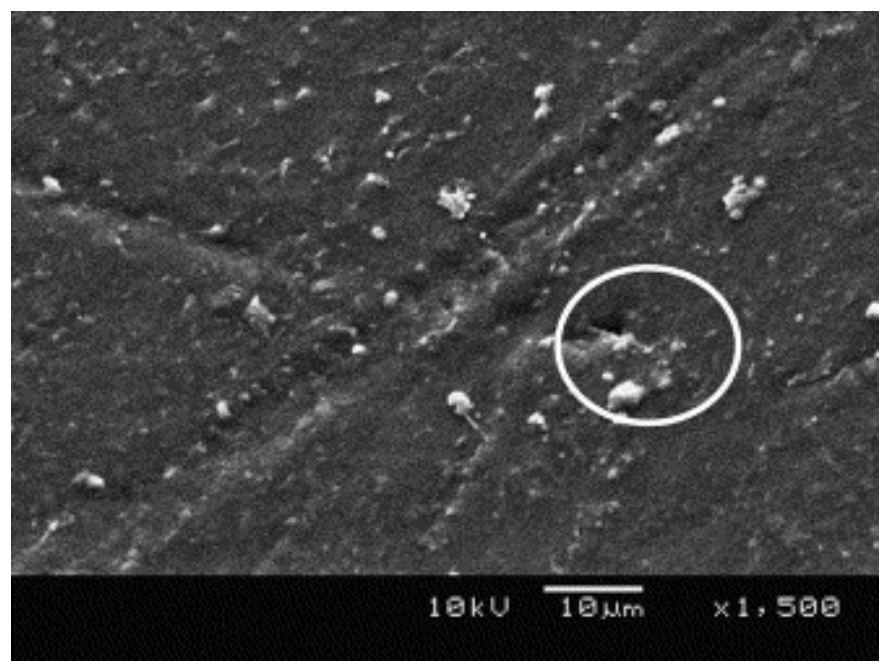

Fig. 15. Final position of particle causing damage to bearing surface (magnification $1500 \times)$.

To eliminate PMMA as a third-body wear particle creating the scratch, a back scatter analysis was performed to establish the presence of any foreign particle at the end of the scratch. The back scatter analysis is shown in Fig. 16.

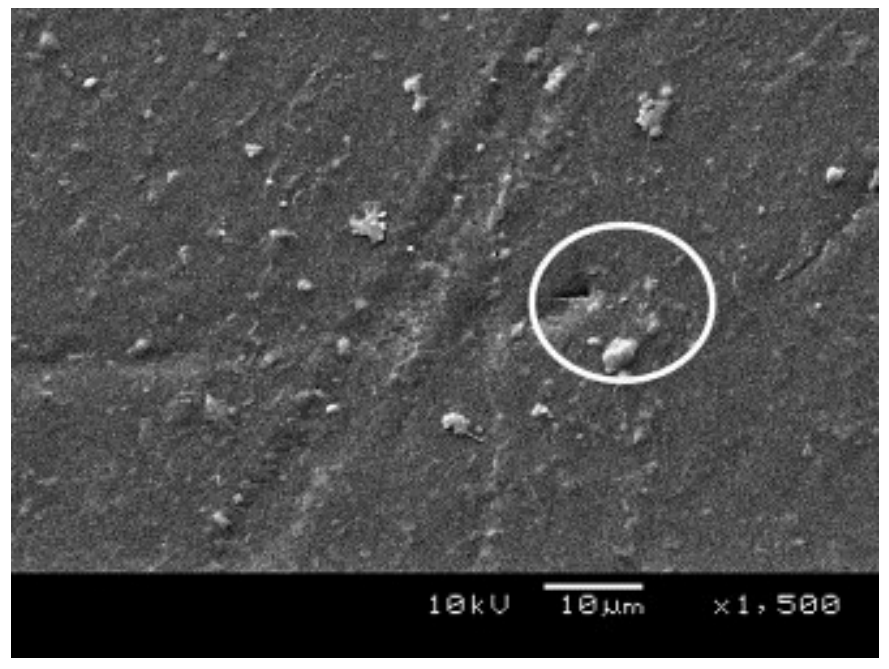

Fig. 16. Electron microscope back scatter analysis of scratch (magnification 1500×). 


\section{openUP (May 2007)}

If the areas encircled in Fig. 15 and Fig. 16 are compared, it shows that there is no foreign particle present that could have caused the damage as seen. There is even wear debris trapped around the ploughing mark that is the same as the base material, UHMWPE.

A further analysis was done on another spot in the same acetabular cup as shown in Fig. 17. This analysis was done closer to the area of adhesion wear. The main scratch can be seen in Fig. 17 with the final damage enlarged in Fig. 18.

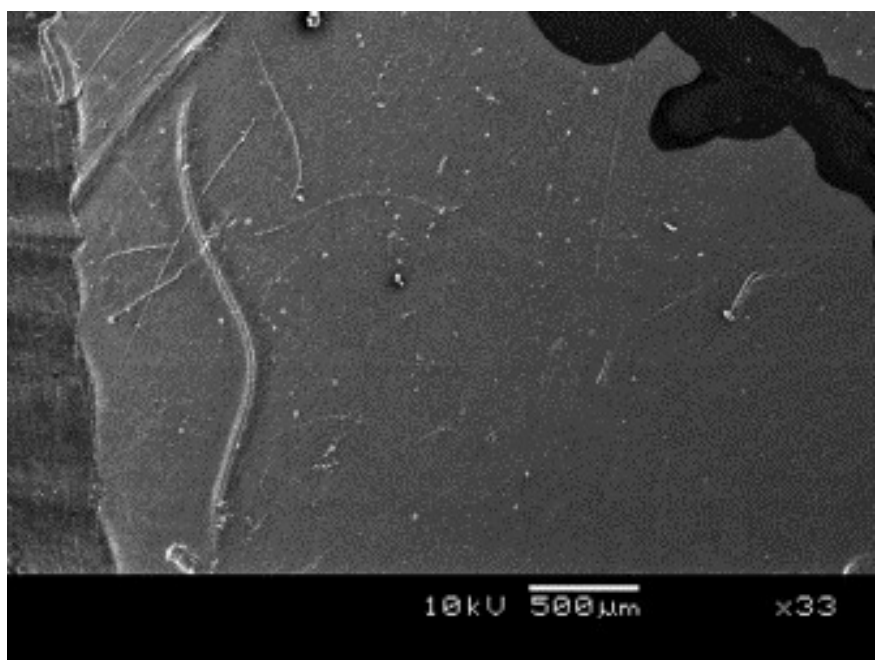

Fig. 17. Scratch on bearing surface (magnification $33 \times$ ).

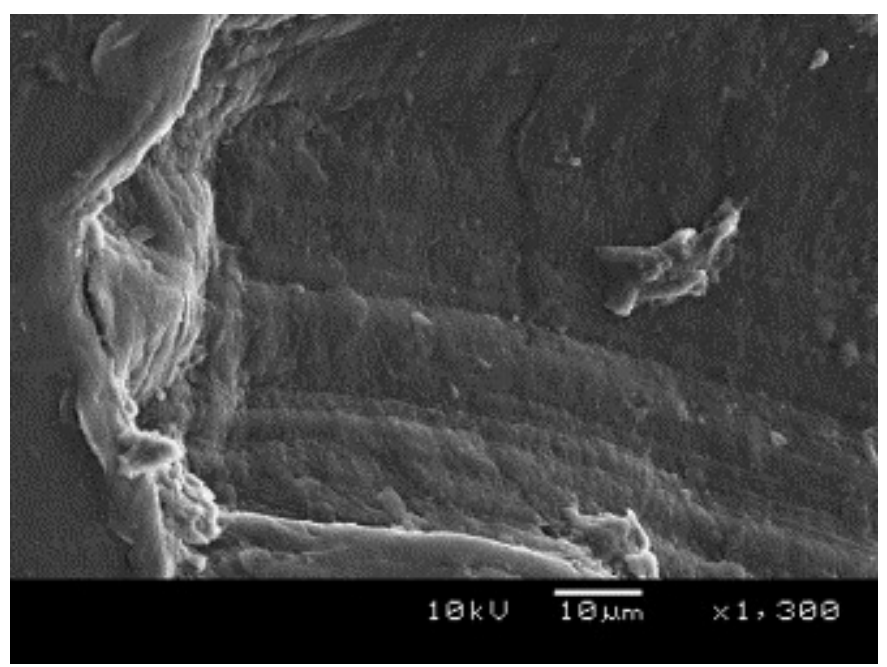




\section{openUP (May 2007)}

Fig. 18. End of scratch on bearing surface (magnification 1300×).

In both these scratch marks, the damage was not caused by a foreign body, but by a wear particle generated during the in vivo use of the implant. The conclusion can be drawn that no foreign body is present in the wear scar. When the damage to the acetabular cup is compared to the wear debris retrieved from tissue surrounding the joint, the resemblance is clear. Typical debris retrieved from the same patient is given in Fig. 19 and Fig. 20.

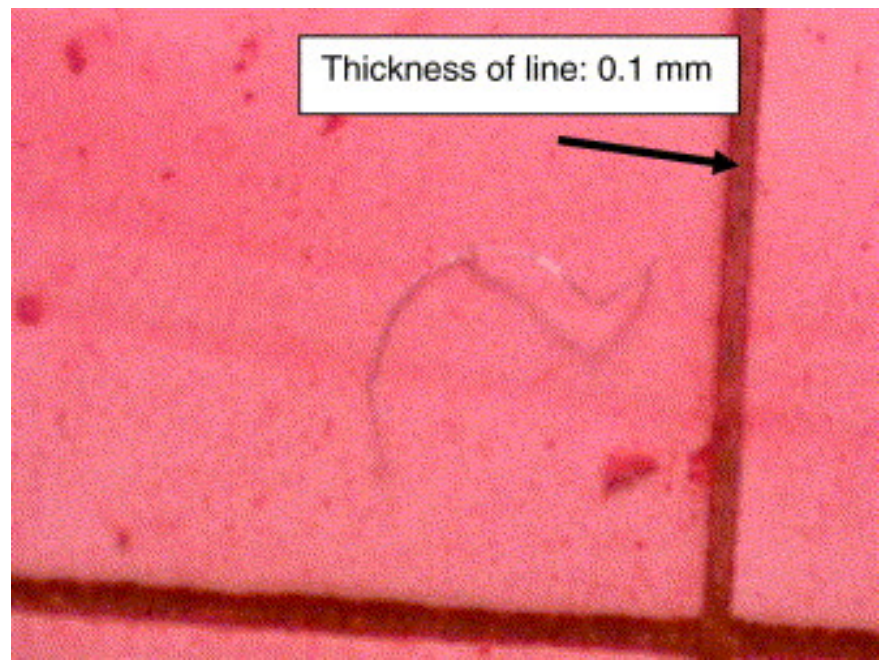

Fig. 19. Whisker-like debris retrieved from patient (magnification 20×).

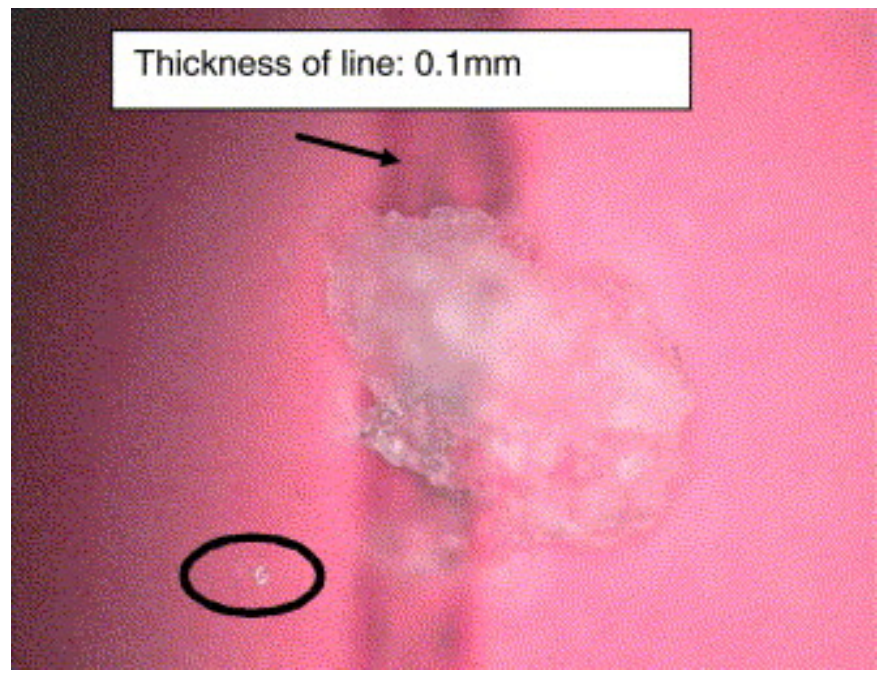

Fig. 20. Debris retrieved from patient (magnification 40×). 
The shape and the appearance of these items of debris suggest that both the whiskers and the droplets were formed under excessive heat conditions. From the literature survey, follows that for UHMWPE temperatures above $40^{\circ} \mathrm{C}$ should be avoided, with short time (seconds) peak temperatures of $80^{\circ} \mathrm{C}$ given by the manufacturers as the absolute maximum [22] and [23].

\subsection{Plastic flow}

During visual observations, areas of material that had plastically flowed under the prevailing pressure were identified. An acetabular cup with the type of plastic flow mentioned is shown in Fig. 21. Under higher magnification, making use of the electron microscope, a number of these areas of plastic flow were identified (Fig. 22 and Fig. 23).

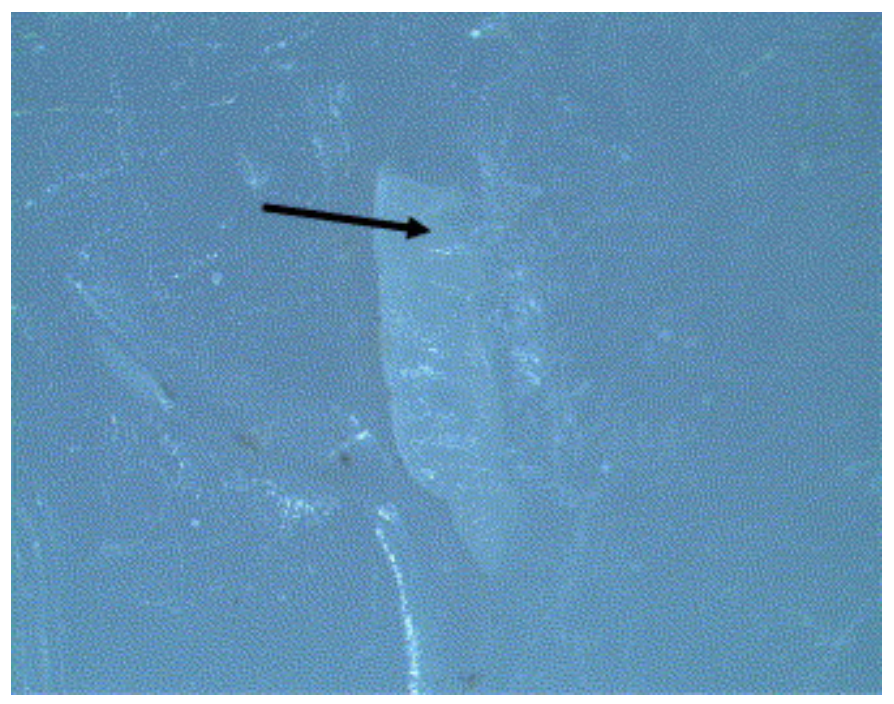

Fig. 21. Plastic flow of material visible in cup (magnification 10×). 


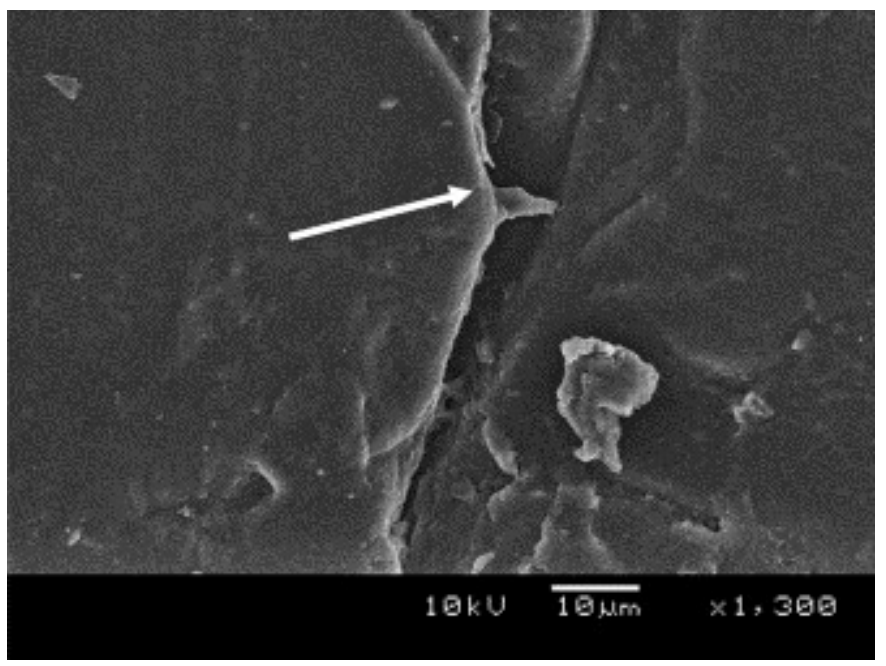

Fig. 22. Plastic flow in acetabular cup (magnification 1300×).

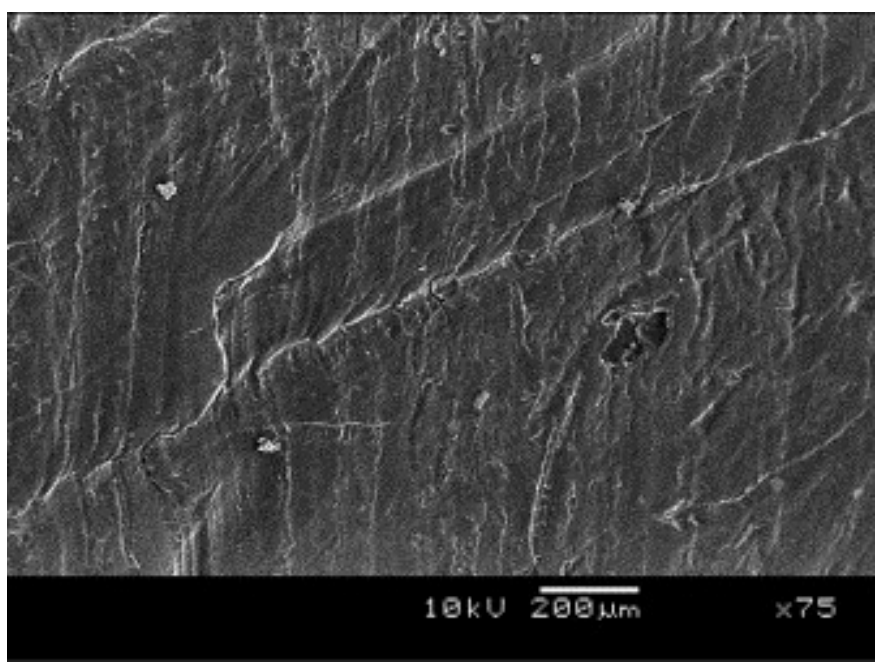

Fig. 23. Area with plastic flow lines visible (magnification $75 \times$ ).

If the higher creep data at elevated temperatures [24] together with the analysis of deposited proteins on the inside of the cup, is taken into account with the resulting conclusion of localised elevated temperatures, it is most probable that the only way this type of plastic flow can occur is that the material at elevated temperatures is squeezed out of the high pressure area to an area of lower pressure. 


\section{openUP (May 2007)}

\subsection{Adhesion wear}

During the initial investigation, areas of adhesion wear were identified. These areas were first identified during the visual examination of the retrieved components as shown in Fig. 12. When the components were treated with dye penetrant spray, these affected areas became visible, as shown in Fig. 24. The areas are characterised by a typical butterfly shape as described by [25], where the surface of the bearing area seemed to be broken up. In some of the cups, the machining marks are also still visible under higher magnification, as shown in Fig. 25. The edges of these areas are very rough and this is indicative of the temperature under which the removal of the material took place.

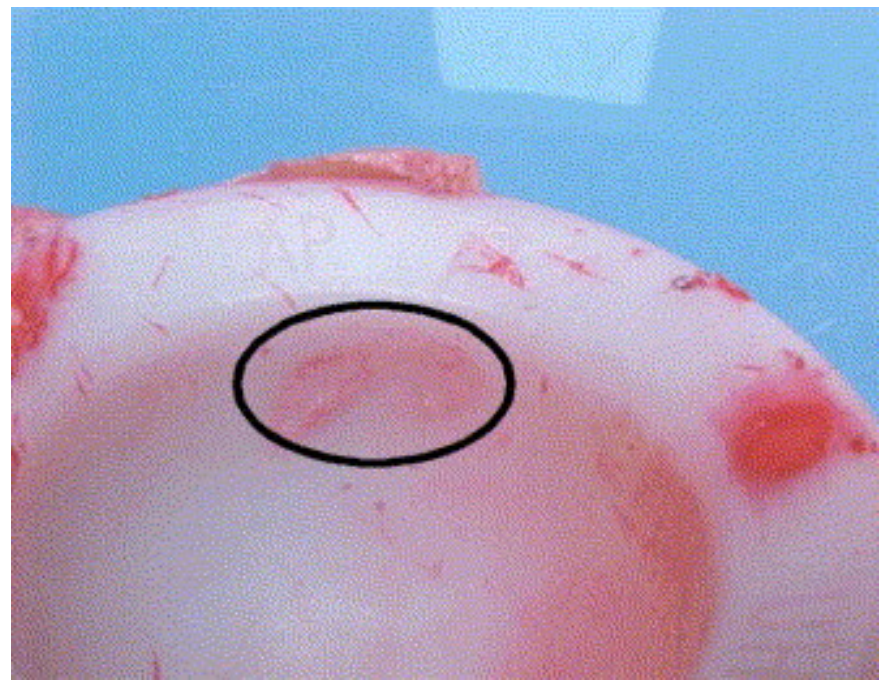

Fig. 24. Butterfly wear pattern on inside of acetabular cup. 


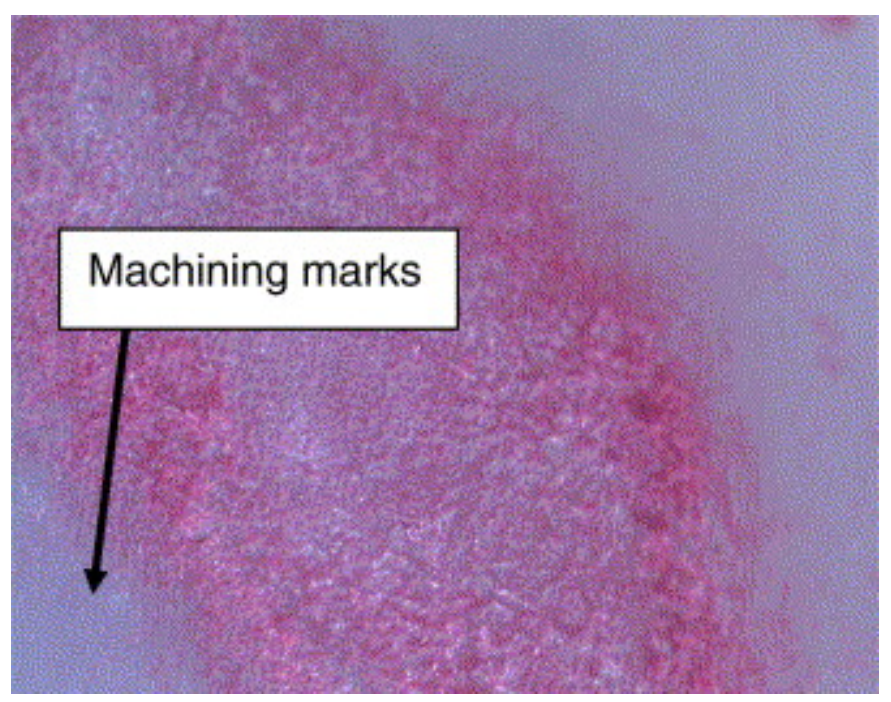

Fig. 25. Area with adhesion wear (magnification 40×) and machining marks still visible.

The area with adhesion wear, as indicated in Fig. 12, was then further investigated making use of the electron microscope. From the data obtained from the electron microscope it is evident that in this area adhesion of the material to the femoral head took place. The surface of the bearing was subsequently ripped, exposing the deeper part of the base material as is shown in Fig. 26.

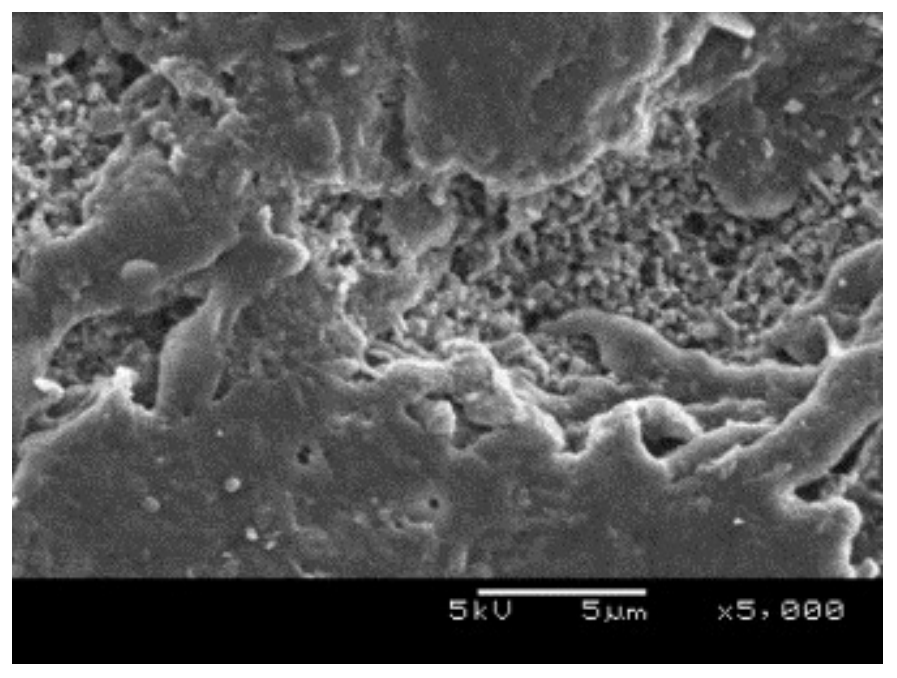

Fig. 26. Area with adhesion wear exposing the base material of the acetabular cup (magnification 5000×). 
The typical particle that was dislodged from the bearing area is shown in Fig. 27. This is also the type of particle that can result in the scratches, as shown in Fig. 17 and Fig. 18. Examining the particle closely (Fig. 27) actually reveals a number of smaller particles that were dislodged and is now adhering to the outer part of the bigger particle. It must be noted that although the particle shown in Fig. 27 was worked out of the high-pressure high-temperature area of the bearing, it was again attached to the base material when the pressure and temperature dropped sufficiently.

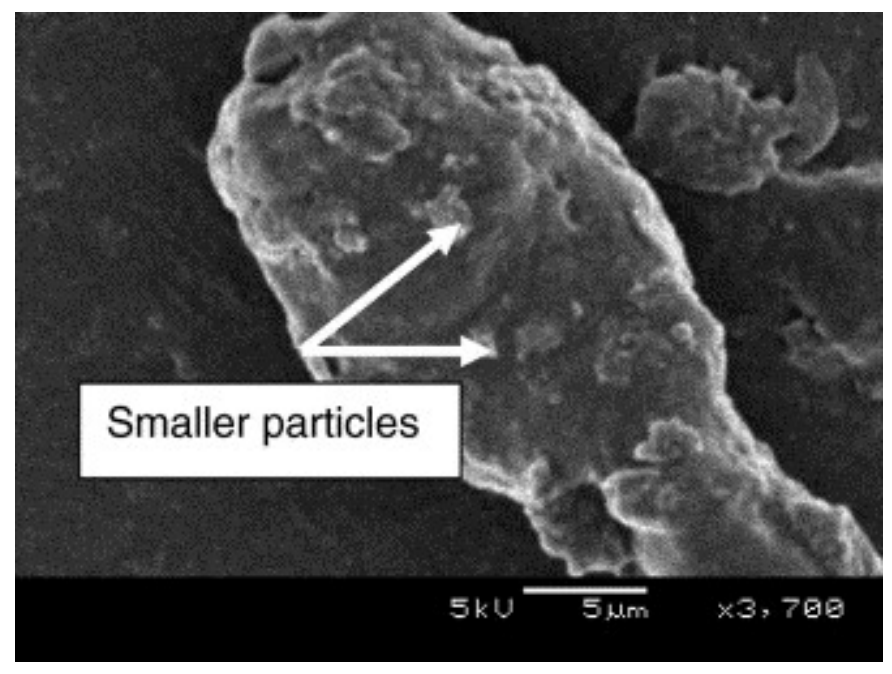

Fig. 27. Wear particle with smaller particles attached to it (magnification 3700×).

The mechanism for the formation of this type of particle can therefore be described as a snowball effect where the smaller particles, which were sufficiently softened by the prevailing head and pressure, adhere to the bigger particle as this was rolling or skidding along on the inside of the acetabular bearing.

A second type of adhesion wear was identified where the surface layer of the acetabular bearing is ripped off in what looks like tile-shaped wear debris, as shown in Fig. 28. If the defect as shown in Fig. 28 is investigated further under higher magnification, it appears that the tile, as shown in Fig. 29, is almost completely loose and is only attached at the one corner. The moment this tile is dislodged, it will form wear debris (third body) that floats around in the joint area. 


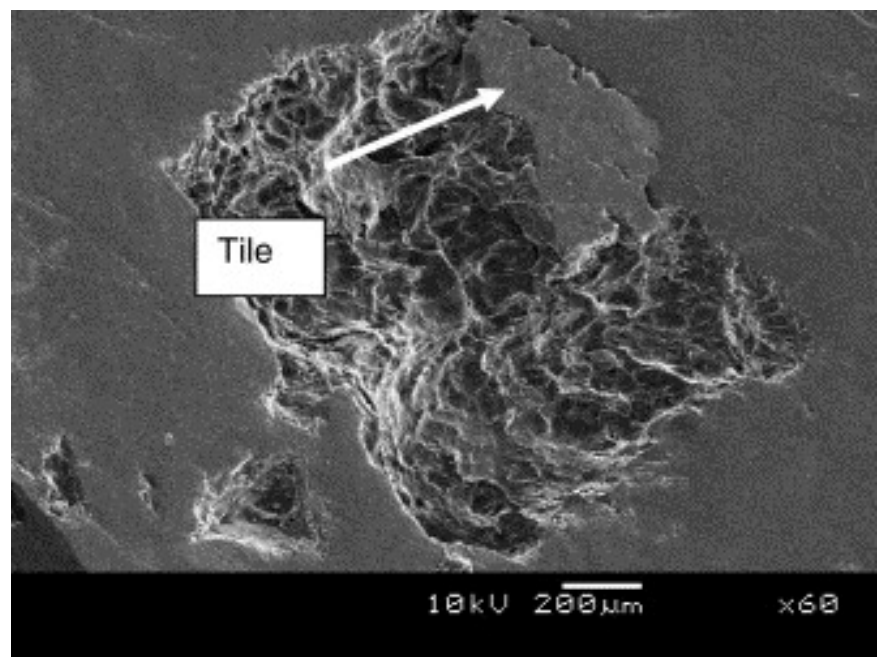

Fig. 28. Area with adhesion wear where a particle is still partly attached to base material (magnification 60×).

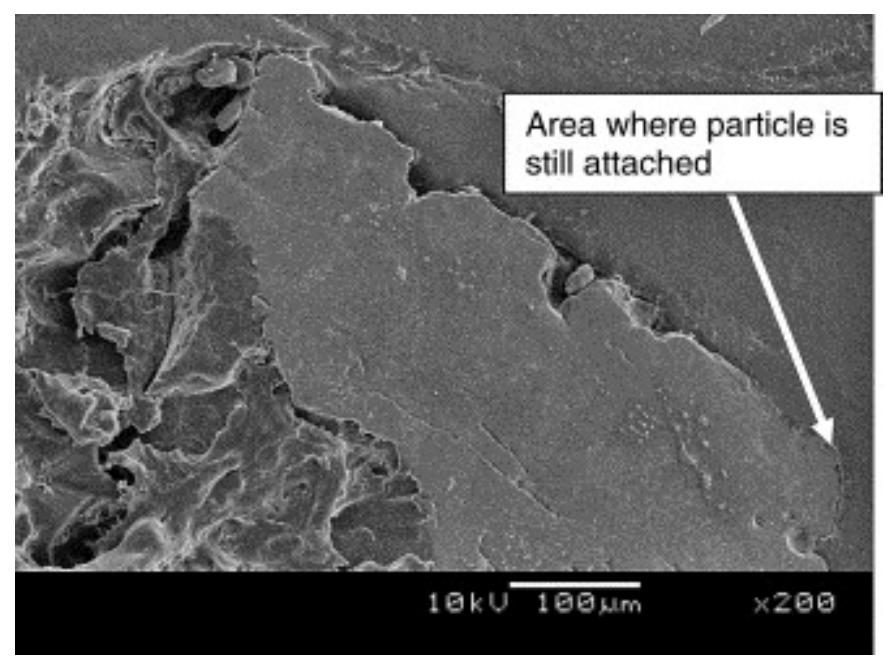

Fig. 29. Adhesion particle about to be broken out of base material (magnification 200×).

\section{Postulate for mechanical failure of acetabular cups}

The shape of the particles as well as the shape of the small craters with the resulting scratches and plastic flow observed can readily be explained as follows: If the bearing load plus the rate of movement is not too high, the temperature will be relatively low and excellent bearing life will be obtained. The heat input into the bearing is determined by 
the product of load and speed $(P \times V)$ [26]. If the $P V$ value increases the surface temperature at the point of highest loading increases accordingly. As the temperature goes up, adhesion between the femoral ball and the socket increases with a resultant higher heat input in the high-stress area (see Fig. 30a). A point is reached where the material has softened sufficiently and the adhesion has increased to the point where the bearing material is dragged along by the ball, in a similar manner to a wear particle being dragged along by a shaft in a rotating plain bearing couple. This leaves behind a crater, with the displaced material trapped between the cooler edges of the crater and the femoral head. Loading will flatten the material removed (Fig. 30b) into a wafer with irregular edges as shown by the retrieved particle in Fig. 20. If, on the other hand, a scratch exists under the wafer, there will be a tendency to extrude material along the scratch as a fibre or whisker as shown in Fig. 19. It should be noted that the pressure in the wafer of removed material will be very high as the wafer will, in effect, be forced between the ball and the cup, effectively raising the ball relative to the cup with the load being mainly supported by the wafer. (Note that the flattened wafer can be forced into the bearing surface.) The particles will with time migrate through the bearing to the surrounding tissue.

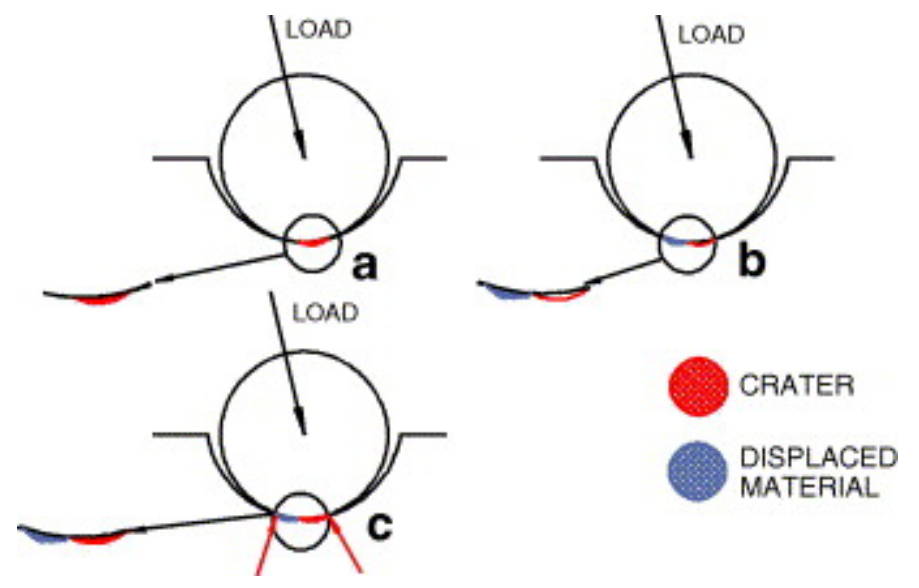

Fig. 30. Steps in wear debris formation in acetabular cup.

A further aspect to consider is that after a crater has been formed, the edges of the crater will be bearing the highest load, as shown in Fig. 30c. The process described above will 
be repeated during the dynamic loading, with the result that the crater will grow in size and in depth, as is commonly observed in retrieved acetabular cups.

The rate of particle migration is expected to be very slow, because of the slow oscillating movement of the femoral head. The process described above must therefore not be regarded as rapid and catastrophic but rather as slow and eventually catastrophic. This is a slow process that is largely activated by high $P V$ incidents.

Inadequate lubrication will accelerate the build-up of heat and therefore will accelerate the wear process. The lack of lubrication can either be contributed to the lack of lubricity in the synovial fluid or the inadequate lubrication model for actually ensuring lubrication on the running surface inside the joint. This lack of lubrication will definitely result in accelerated heat built-up on the bearing surface with the consequential damage as shown.

\section{Conclusion}

The final conclusion of this investigation is that excessive amounts of wear debris are generated due to the localised overheating of the bearing couple as a result of insufficient lubrication. The localised heat build-up results in excessive amounts of wear debris being generated and deposited in the joint area causing osteolysis. The resulting craters left after removal of the particles adhering to the counter surface give rise to stress raisers that result in cracks forming in the UHMWPE acetabular cups. These cracks can result in catastrophic failures. 
openUP (May 2007)

\section{References}

[1] J. Charnley, Low friction arthroplasty of the hip - theory and practice, SpringerVerlag, Berlin (1979).

[2] M. Schaldach and D. Hohmann, Advances in artificial hip and knee joint technology, Engineering in medicine vol. 2, Springer-Verlag (1976).

[3] Mallchau H, Herberts P, Garellick G, Söderman P, Eisler T. Prognosis of total hip replacement, update of results and risk ratio, analysis for revision and re-revision. Swedish National Hip Arthroplasty Register, 2000, 1979-2000.

[4] M.H. Huo and S.M. Cook, What’s new in hip arthroplasty, J Bone Joint Surg 83A (2001) (10), pp. 1598-1610.

[5] Davidson D, Graves S, Batten J, Cumberland W, Fraser J, Harris J, et al. Australian Orthopaedic Association National joint replacement registry. Annual Report, Adelaide AOA, 2002.

[6] Havelin LI, Furnes O, Espehaug B. The Norwegian Arthroplasty Register. Annual Report, 2003.

[7] Davidson D, Graves S, Batten J, Cumberland W, Fraser J, Harris J, et al. Australian Orthopaedic Association National Joint Replacement Registry. Annual Report, Adelaide AOA, 2003.

[8] A. Claus, C.J. Sychterz, R.H. Hopper and C.A. Engh, Pattern of osteolysis around two different cementless metal backed cups, J Arthroplasty 16 (2001) (8), pp. 177-182.

[9] J.H. Dumbleton, T. Manley and A.E. Avram, A literature review of the association between wear rate and osteolysis in total hip arthroplasty, J Arthroplasty 17 (2002) (5), pp. 649-661. 
[10] M.T. Manley, J. D’Antonio, W.N. Capello and A.A. Edidin, Osteolysis: a disease of access to fixation interfaces, Clin Orthop 1 (2002) (405), pp. 129-137.

[11] P. Foguet, F. Hashmi and T. Lawrence, Case report: metaphyseal osteolysis around a titanium reconstruction nail, Int J care Injured 34 (2003), pp. 374-377.

[12] A.P. Oakley and J.A. Matheson, Rapid osteolysis after hip arthroplasty in paget's disease, J Arthroplasty 18 (2003) (2), pp. 204-207.

[13] J.M. Wilkinson, A.J. Hamer, A. Rogers, I. Stockley and R. Eastell, Bone mineral density and biochemical markers of bone turnover in aseptic loosening after total hip arthroplasty, J Orthopaed Res (2003), p. 21.

[14] ISO 12891-3. Retrieval and analysis of surgical implants, Part 3. Analysis of retrieved polymeric surgical implants, 2000.

[15] Burger NDL. Failure analysis of ultra high molecular weight polyethylene acetabular cups. PhD thesis, University of Pretoria, 2006.

[16] J.P. Paul, Loading on normal hip and knee joints and on joint replacements, advances in artificial hip and knee joint technology, Springer-Verlag (1976) [p. 53-70].

[17] G. Bergmann, F. Graichen and A. Rohlmann, Hip loading during walking and running, measured in two patients, J Biomech 26 (1993) (8), pp. 969-990.

[18] ISO 14242-1. Implant for surgery - wear of total hip joint prosthesis, Part 1: Loading and displacement parameters for wear testing machines and corresponding environmental conditions for test, 2002.

[19] M. Jasty, D.D. Goetz and C.R. Bragdon, Wear of polyethylene acetabular components in total hip arthroplasty: an analysis of one hundred and twenty eight components retrieved at autopsy or revision operations, J Bone Joint Surg 79-A (1997), pp. 349-358. 
[20] T.P. Schmalzried and J.J. Callaghan, Wear in total hip and knee replacements, $J$ Bone Joint Surg 81-A (1999), pp. 115-136.

[21] K. Haraguchi, N. Sugano, T. Nishii, T. Sakai, H. Yoshikawa and T. Ohzona, Influence of polyethylene and femoral head surface quality on wear: a retrieval study, Int Orthopaed 25 (2001), pp. 29-34.

[22] Engineering material handbook, vol. 2. ASM International; 1987. 167 - 1702.

[23] Material data sheet. UHMWPE, Poli HiSolidur, 1999.

[24] N.D.L. Burger and E. Fourie, The impact of the gamma irradiation dose during sterilization and crosslinking on the creep properties of ultra high molecular weight polyethylene (UHMWPE), $R \& D J$ (2005) (April).

[25] A. Wang, A. Essner, V.K. Polineni and C. Stark, Wear mechanisms and wear testing of ultra high molecular weight polyethylene in total joint replacement, Polyethylene wear in orthopaedics implants workshop, Society of Biomaterials, Minneapolis (1997), pp. 418.

[26] I.M. Hutchings, Tribology, friction and wear of engineering materials, Arnold (1992).

眶Corresponding author. Tel.: +27 12420 3764; fax: +27 124202047 . 